\title{
Contribution à l'étude des entérocoques et de leurs aptitudes technologiques* Aptitude à la dégradation des acides aminés
}

\author{
par \\ J. L. SCHMIDT et J. LENOIR \\ avec la collaboration de M. DO NGOC \\ et l'aide technique de Annick NORMAND et Ch. NORMAND \\ Laboratoire de Recherche de la Chaire de Technologie (I.N.R.A.) \\ Institut National Agronomique Paris-Grignon \\ Centre de Grignon (78850)
}

\section{INTRODUCTION}

Au cours de la maturation des fromages, la dégradation des matières azotées sous l'action des enzymes, notamment des enzymes d'origine microbienne, ne se limite pas à l'hydrolyse des protéines. Les acides aminés libérés sont en effet susceptibles d'être à leur tour transformés selon divers mécanismes ; ils peuvent être désaminés par voie oxydative ou par voie réductrice ; ils peuvent participer à des réactions de transamination et de décarboxylation ; certains peuvent subir des réactions d'hydrolyse. A partir des acides aminés libres, de nombreux composés peuvent ainsi se former (acides organiques volatils, amines, ammoniac, composés carbonylés, sulfurés, phénoliques) et ces composés jouent un rôle important dans le développement de la saveur et de l'arôme des fromages (Kosikowski et Mocquot, 1958 ; Jacquet et Lenoir, 1969).

Les études sur le catabolisme des acides aminés, par les streptocoques du groupe $\mathrm{D}$, ont généralement montré que cette dégradation est assez limitée (Deibel, 1964 a) ; toutefois, certaines observations récentes tendent à infirmer ce point de vue. Il a, en effet, été mis en évidence que l'activité des entérocoques pouvait se manifester non seulement sur l'arginine et la tyrosine, mais également sur la sérine, le tryptophane, la phénylalanine et certaines amines telles l'agmatine et la canavanine. Dans ces conditions, il n'était pas sans intérêt de

\footnotetext{
* Travail réalisé dans le cadre d'un contrat de la Délégation Générale à la Recherche Scientifique et Technique. Contrat $\mathrm{n}^{\circ} 6901935$ sur la mise au point d'une technologie mécanisée de fabrication des pâtes molles.
} 
vérifier l'action de ce groupe microbien sur un mélange d'acides aminés.

Les réactions de décarboxylation tiennent, dans l'affinage des fromages, une place importante (Hosono et Tokita, 1969). On sait que seuls six acides aminés sont susceptibles d'être décarboxylés : lysine, ornithine, arginine, tyrosine, histidine et acide glutamique (Gale, 1946). Les enzymes responsables sont actives à un $\mathrm{pH}$ moyen situé vers 4,0-5,0, exception faite de la L-lysine décarboxylase dont le $\mathrm{pH}$ optimal d'action se situe vers 2,5-3,0. Les amines formées par ces réactions peuvent participer au développement de la saveur des fromages. Il en est ainsi de la tyramine, trouvée en proportions notables dans divers types de pâtes affinées (Kosikowski et Dahlberg, 1948 ; Raibaud et al., 1959), et dont la formation serait liée au développement de la flaveur du Cheddar (Dahlberg et Kosikowski, 1948), bien qu'elle ne semble pas appartenir au groupe des substances responsables de la saveur typique (Dacre, 1953).

L'activité décarboxylasique des entérocoques a déjà fait l'objet de plusieurs études. Les travaux de Gale (1940 a, 1940 b, 1940 c, 1946) et de Dahlberg et Kosikowski (1948) ont notamment montré que ces micro-organismes étaient actifs sur la tyrosine. Barnes et Ingram (1955) ont également relevé une telle activité en mentionnant sa variabilité au sein du groupe et des espèces, particulièrement chez S. faecium. Certains auteurs (Mc Gilvery et Cohen, 1948 ; Bachrach et al., 1958 ; Lestrovaya et Mardashev, 1960) ont mis aussi en évidence une activité décarboxylasique sur la phénylalanine chez S. faecalis mais, selon Deibel (1964 a), cette activité serait limitée. Il a, en outre, été fait état d'une décarboxylase active sur le tryptophane (Silvermann, 1954).

Le rôle des désaminases microbiennes, dans l'affinage des fromages, ne semble pas avoir fait l'objet d'études systématiques. Il s'agit pourtant de systèmes enzymatiques importants notamment dans les fromages à pâte molle, tel le Camembert (Kosikowski et Mocquot, 1958). Ces enzymes, dont l'optimum d'activité se situe vers $\mathrm{pH}$ 7-8, peuvent exercer leur action lorsque les pâtes, à la suite de l'intervention des moisissures, évoluent vers la neutralité. Les acides aminés, alors attaqués, donnent naissance à de l'ammoniac et, par voie oxydative, à un acide $\alpha$-cétonique, ou, par voie réductrice, à un acide organique (Mahler et Cordes, 1968).

Kristoffersen et Nelson (1955) ont mis en évidence, chez Lactobacillus casei, une aptitude à la désamination de la sérine, de la cystéine, et de l'asparagine, à un $\mathrm{pH}$ optimal situé vers 8,3. D'autres recherches effectuées sur E. coli (Gale et Stephenson, 1938 ; Wood et Gunsalus, 1949), ont montré que ce micro-organisme est capable de désaminer la sérine et la thréonine.

Très peu d'études ont été consacrées à l'activité désaminasique des entérocoques; seuls, Deibel et Niven (1960) ont noté une dégra- 
dation de la sérine, et cette action serait d'ailleurs très limitée, puisque réalisée uniquement par $S$. faecalis.

L'importance de ces diverses réactions dans l'affinage des fromages est telle que dans une étude des caractères technologiques des entérocoques et de leurs possibilités d'emploi en fromagerie (Schmidt et Lenoir, 1972 a, 1972 b), il nous a paru nécessaire d'inclure l'aptitude à la dégradation des acides aminés. Cette recherche a comporté la mise en évidence des possibilités d'action sur un mélange d'aminoacides, une détermination de l'activité des systèmes décarboxylasique et désaminasique ainsi qu'une étude de la dégradation de l'arginine qui s'effectue selon un mécanisme particulier (Niven et al., 1942).

\section{I. - PROTOCOLES EXPERIMENTAUX}

\subsection{Action sur un mélange d'acides aminés}

Cette recherche a été effectuée sur un substrat constitué par un mélange de 16 acides aminés. Le $\mathrm{pH}$ a été ajusté soit à $5,6, \mathrm{pH}$ proche de celui de nombreuses pâtes fromagères et du $\mathrm{pH}$ optimal d'action des décarboxylases, soit à $\mathrm{pH} 7,8, \mathrm{pH}$ favorable aux réactions de désamination.

\subsubsection{ChOIX DES SOUCHES ET CONDITIONS DE CULTURE}

Les souches éprouvées appartiennent à notre collection de streptocoques du groupe D (Schmidt et Lenoir, 1972 a). Une souche de chaque espèce a été retenue : $S$. durans L 41, S. faecium EM 68, S. faecalis C 35, S. faecalis var. liquefaciens L 38.

Avant essai, chaque souche est repiquée deux fois, à $24 \mathrm{~h}$ d'intervalle, sur lait tournesolé, et cultivée à $37^{\circ} \mathrm{C}$. Elle est ensuite inoculée au taux de 1 p. 100 sur 21 du milieu suivant placé en ballons de 31 : trypticase (Mérieux), 1,7 p. 100 ; bactosoytone (Difco), 0,5 p. 100 ; $\mathrm{K}_{2} \mathrm{HPO}_{4}, 0,25$ p. 100 ; $\mathrm{NaCl}, 0,5$ p. 100 ; glucose, 0,5 p. $100 ; \mathrm{pH} 7,3$ après stérilisation par autoclavage $115^{\circ} \mathrm{C} / 20 \mathrm{mn}$.

Lors de l'incubation effectuée durant $24 \mathrm{~h}$ à $37^{\circ} \mathrm{C}$, les cultures sont maintenues à un $\mathrm{pH}$ voisin de 6,5 par additions régulières d'une solution stérile de soude $2 \mathrm{~N}$.

\subsubsection{DÉTERMination DE L'ACTIVITÉ}

- Préparations enzymatiques : les cellules microbiennes sont collectées par centrifugation, à $2000 \mathrm{~g}$ pendant $30 \mathrm{mn}$, à l'aide d'une centrifugeuse MSE Mistral $4 \mathrm{~L}$ réfrigérée à $+4^{\circ} \mathrm{C}$. Les culots cellulaires sont lavés deux fois avec un tampon phosphate $\mathrm{M} / 15 \mathrm{pH} 7,0$, puis remis en suspension à la concentration de 20 p. 100 dans un tampon mixte (acétate-borate-phosphate) 0,25 M, pH 5,4 ou pH 7,5. 
La préparation ainsi obtenue (suspension cellulaire) est désignée $P_{1}$. A partir d'une fraction de cette préparation, il est procédé à la désintégration des cellules, par broyage mécanique, à l'aide de l'appareil Braun (type 2876) : $15 \mathrm{ml}$ de suspension sont agités pendant $2 \mathrm{mn} 30 \mathrm{~s}$ dans une fiole de $60 \mathrm{ml}$ en présence de $40 \mathrm{~g}$ de billes de verre (diamètre : 0,11-0,12 $\mathrm{mm}$ ) ; l'échauffement exagéré du mélange est évité par refroidissement à l'aide d'anhydride carbonique liquide ; l'efficacité de la destruction est de l'ordre de 99 p. 100. La suspension broyée est alors centrifugée à $2500 \mathrm{~g}$ pendant $10 \mathrm{mn}$ de façon à éliminer les billes de verre et les débris cellulaires. Le surnageant correspond à la préparation enzymatique endocellulaire $\mathrm{P}_{2}$.

Les préparations $\mathrm{P}_{1}$ et $\mathrm{P}_{2}$ sont immédiatement utilisées pour les déterminations d'activité.

- Conditions de digestion : l'activité enzymatique des préparations est déterminée sur un substrat constitué par le mélange des formes DL des acides aminés suivants : acide aspartique, thréonine, sérine, acide glutamique, glycine, alanine, valine, cystéine, méthionine, isoleucine, leucine, tyrosine, phénylalanine, lysine, histidine et arginine; la concentration de chaque acide aminé est de 5 umoles par ml et le pH de la solution est ajusté à 5,0 .

Les mélanges réactionnels ont la composition suivante :

Préparation enzymatique $\left(\mathrm{P}_{1}\right.$ ou $\left.\mathrm{P}_{2}\right) \ldots \ldots \ldots \ldots, 0,5 \mathrm{ml}$

Solution d'acides aminés .............. $1 \mathrm{ml}$

Tampon mixte $0,25 \mathrm{M}, \mathrm{pH} 5,4$ ou 7,5 . . . . $0,5 \mathrm{ml}$

La réaction s'effectue au bain-marie à $40^{\circ} \mathrm{C}$ dans des tubes à hémolyse soigneusement bouchés. Après $3 \mathrm{~h}$ d'incubation, l'action enzymatique est arrêtée par addition de $1 \mathrm{ml}$ d'acide trichloracétique à $36 \mathrm{p}$. 100. La solution est ensuite filtrée sur papier Whatman $n^{\circ} 41$, centrifugée $10 \mathrm{mn}$ à $2500 \mathrm{~g}$, puis ajustée à $\mathrm{pH} 1,6-1,8$. Elle constitue l'échantillon sur lequel sont dosés les acides aminés. Pour chaque préparation, les témoins sont constitués par les mélanges réactionnels non incubés et traités dans les mêmes conditions. En ce qui concerne la suspension cellulaire (préparation $P_{1}$ ), il a été vérifié que, par incubation $3 \mathrm{~h}$ à $40^{\circ} \mathrm{C}$ en solution tampon de concentration et de $\mathrm{pH}$ analogues à ceux du mélange réactionnel, il n'y avait pas libération d'acides aminés.

- Séparation et dosage des acides aminés libres : la séparation et le dosage des acides aminés sont effectués par chromatographie d'échange d'ions sur une prise d'essai de $0,1 \mathrm{ml}$ de filtrat. Le dispositif d'analyse automatique mis en œuvre est celui préconisé par Technicon : chromatographie de $5 \mathrm{~h}$ sur une colonne de résine "Chromobeads " type $C_{2}$ de $750 \times 6 \mathrm{~mm}$, à la température de $58^{\circ} \mathrm{C}$. L'élution est réalisée par un gradient de $\mathrm{pH}$ de 2,75 à 6,10 . L'analyse de l'éluat est effectuée par addition de ninhydrine et de sulfate d'hydrazine en atmosphère d'azote (fig. 1). Après développement de 
la réaction colorée par chauffage à $95^{\circ} \mathrm{C}$, le mélange refroidi passe dans un colorimètre et les variations de la densité optique mesurée à $570 \mathrm{~nm}$ sont enregistrées (Do Ngoc et al., 1971).

La surface des pics est déterminée par triangulation. Afin de corriger les variations possibles dans le développement de coloration, un étalon interne, la norleucine, est introduit dans chaque chromatogramme.

Pour chaque acide aminé, on compare sa concentration dans le mélange réactionnel incubé à sa concentration dans le mélange témoin.

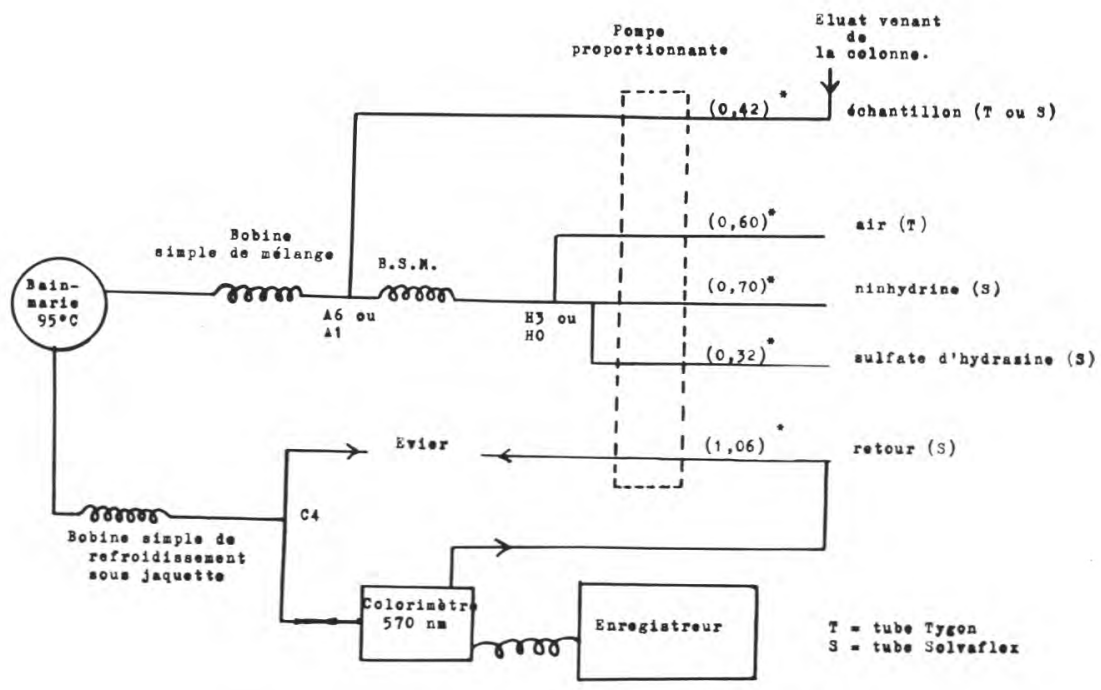

fig. 1

Schéma du dispositif d'autoanalyse pour le dosage des acides aminés

* Débit des tubes en $\mathrm{ml} / \mathrm{mn}$.

(Références des pièces selon la nomenclature Technicon).

\subsection{Activité des décarboxylases}

Les techniques de mise en évidence de la décarboxylation des acides aminés sont nombreuses. Sharpe (1948), étudiant les streptocoques, et Møller (1955), les entérobactéries, ont utilisé la méthode qualitative de Gale (1940 c) fondée sur la modification de pH qui se produit dans le milieu de culture avec la transformation de l'acide aminé en amine correspondante. On peut aussi réaliser une estimation quantitative, soit par dosage de l'acide aminé avant et après 
réaction, soit par dosage de l'amine formée (Kosikowski et Dahlberg, 1948 ; Woiwod, 1949 ; Proom et Woiwod, 1949 ; King et Fletcher, 1950 ; Raibaud et al., 1959). Plus souvent, les auteurs déterminent l'activité décarboxylasique par dosage du gaz carbonique libéré dans la réaction ; pour ce faire, Gale (1946), notamment, utilise la technique manométrique de Warburg.

Ces diverses méthodes sont longues et, par suite, difficiles à mettre en œuvre sur un grand nombre de souches ; aussi avons-nous choisi la méthode d'analyse mise au point par Leclerc $(1966,1967)$ avec le dispositif autoanalyseur Technicon, méthode fondée sur une mesure de la décoloration d'une solution alcaline de phénolphtaléine.

L'activité décarboxylasique est déterminée par dosage du gaz carbonique dégagé par la suspension microbienne d'une part en l'absence et d'autre part en présence d'une solution tampon de l'acide aminé correspondant.

\subsubsection{Préparation des suspensions cellulaires}

Les 22 souches testées dans cette épreuve appartiennent à notre collection de streptocoques du groupe D sélectionnés sur la base de leur pouvoir acidifiant et éprouvés pour leurs aptitudes à la production de composants d'arôme et à la protéolyse.

Les souches sont au préalable cultivées sur lait tournesolé, puis sur milieu TGL (trypticase Mérieux, 2 p. 100 ; glucose, 2 p. 100 ; extrait de levure Mérieux, 0,1 p.100) pH 6,4, stérilisé par autoclavage $20 \mathrm{mn}$ à $115^{\circ} \mathrm{C}$.

Ces milieux sont ensemencés au taux de 2 p. 100 et incubés $24 \mathrm{~h}$ à $37^{\circ} \mathrm{C}$. Les précultures sont ensuite repiquées au taux de 2 p. 100 dans $1 \mathrm{l}$ de milieu TGL. Après incubation $24 \mathrm{~h}$ à $37^{\circ} \mathrm{C}$, les cultures sont centrifugées, $30 \mathrm{mn}$ à $2000 \mathrm{~g}$, à l'aide d'une centrifugeuse MSE Mistral $4 \mathrm{~L}$, réfrigérée à $+4^{\circ} \mathrm{C}$. Les culots cellulaires sont lavés deux fois avec $100 \mathrm{ml}$ de tampon acétate $0,2 \mathrm{M} \mathrm{pH} \mathrm{4,0}$ ou 5,6 , et les cellules récoltées sont mises en suspension au taux de 20 p. 100 dans le même tampon.

Les déterminations de l'activité décarboxylasique, effectuées immédiatement après la préparation des suspensions, sont réalisées sur deux cultures différentes d'une même souche et chaque culture est elle-même testée en double.

\subsubsection{RÉACTIFS}

Les réactifs préparés pour la production, la libération et le dosage du gaz carbonique sont ceux décrits par Leclerc (1967).

- Substrat en solution tampon acétate : Ig de l'acide aminé sur lequel on se propose d'étudier l'activité décarboxylasique est dissous dans $100 \mathrm{ml}$ de tampon acétate $0,2 \mathrm{M}, \mathrm{pH} 4,0$ ou 5,6, additionnés de $0,1 \mathrm{ml}$ de tween 20 . 
Solution formolée

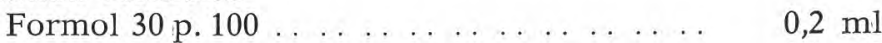

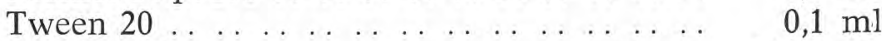

Eau distillée . . . . . . . . . . . . . . . . . q.s.p. . . $100 \quad \mathrm{ml}$

Solution pour la libération du $\mathrm{CO}_{2}$

Acide sulfurique N . . . . . . . . . . . . . . . . . $1000 \quad 1000$

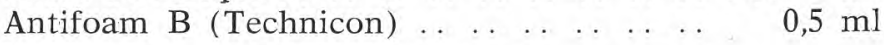

Réactif à la phénolphtaléine

Tampon carbonate-bicarbonate

$\left(\mathrm{Na}_{2} \mathrm{CO}_{3} \mathrm{M} / \mathrm{NaHCO}_{3} \mathrm{M}=1: 2 \mathrm{v} / \mathrm{v}\right) \ldots \ldots . . .3,6 \mathrm{ml}$

Phénolphtaléine (solution à 1 p. 100 dans

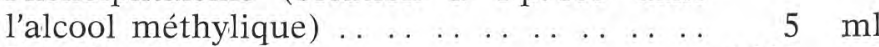

Eau distillée .............. . ..s.p. .. $1000 \quad \mathrm{ml}$

\subsubsection{TECHNiQue OPÉRATOIRE}

Les différentes étapes de l'analyse sont schématisées sur la figure 2 .

La suspension microbienne et la solution tampon $\mathrm{pH} 4,0$ ou $\mathrm{pH}$ 5,6 contenant ou non l'acide aminé, sont prélevées à travers la pompe proportionnante et homogénéisées dans la bobine de mélan-

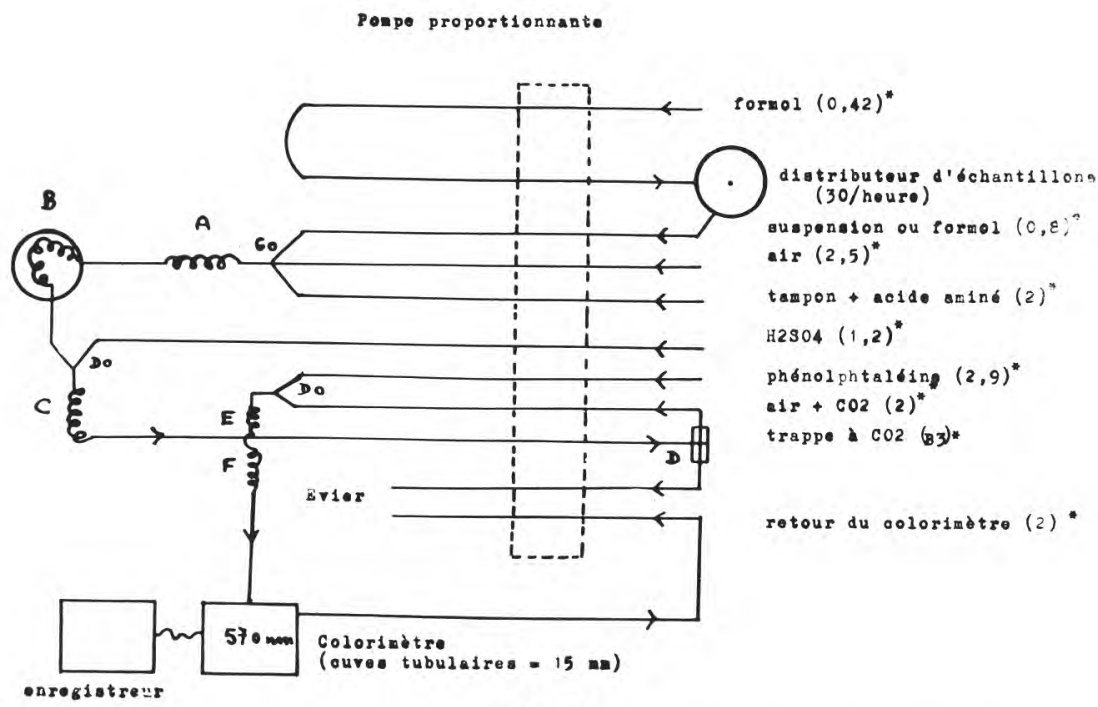

fig. 2

Schéma du dispositif d'autoanalyse pour l'étude des décarboxylases d'acides aminés

* Débit des tubes tygon en $\mathrm{ml} / \mathrm{mn}$.

(Références des pièces selon la nomenclature Technicon). 
ge A. La suspension diluée passe dans la bobine d'incubation B, immergée dans un bain-marie réglé à $37^{\circ} \mathrm{C}$. Le taux de gaz carbonique produit par respiration est mesuré sur la suspension témoin, en présence de la seule solution tampon. Lorsque les cellules sont en contact avec une solution d'acide aminé (suspension essai), une quantité supplémentaire de $\mathrm{CO}_{2}$ est libérée par décarboxylation si le micro-organisme élabore une décarboxylase de l'acide aminé essayé. Avec la bobine d'incubation utilisée, tube de verre de $25 \mathrm{~m}$ de longueur et de 1,6 mm de diamètre interne, le temps d'incubation est de $24 \mathrm{mn}$.

Le gaz carbonique produit par respiration ou décarboxylation est libéré à la sortie de la bobine $\mathrm{B}$ par addition d'acide sulfurique $\mathrm{N}$ et passage dans la bobine de mélange $\mathrm{C}$. $\mathrm{Le} \mathrm{CO}_{2}$ tend à passer alors à l'état gazeux dans les bulles d'air qui segmentent l'échantillon. Le flux est pompé à travers le séparateur gaz-liquide $\mathrm{D}$ (trappe à $\mathrm{CO}_{2}$ ) : l'air plus ou moins chargé de gaz carbonique est séparé de la phase liquide et est aspiré par la pompe proportionnante tandis que la phase liquide et une faible partie de la phase gazeuse sont éliminées. Selon Leclerc (1967), 80 p. 100 de la phase gazeuse seraient ainsi extraits et utilisables pour le dosage.

L'air enrichi en $\mathrm{CO}_{2}$ vient segmenter le réactif de la phénolphtaléine. Le contact entre phase gazeuse et solution alcaline est assuré par passage dans les deux bobines de mélange successives $\mathrm{E}$ et $\mathrm{F}$. La neutralisation provoquée par l'anhydride carbonique se traduit par une décoloration de la solution donc par une diminution de l'absorption qui est mesurée à $570 \mathrm{~nm}$. La concentration en gaz carbonique est calculée par comparaison avec une courbe étalon établie, avant chaque série de déterminations, avec une solution molaire de $\mathrm{Na}_{2} \mathrm{CO}$ dans l'intervalle des teneurs 0 à $40 \mathrm{meq}$. L'activité décarboxylasique correspond à la différence ( $\mathrm{CO}_{2}$ libéré en présence de l'acide aminé - CO. libéré en l'absence de l'acide aminé).

L'introduction de suspensions bactériennes rend nécessaire une décontamination du circuit (Leclerc, 1967) ; ainsi, une solution de formol à 0,2 p. 100 est-elle aspirée pendant $1 \mathrm{mn}$ après chaque prise d'échantillon.

\subsection{Activité des désaminases}

Les réactions de désamination peuvent être mises en évidence et estimées quantitativement par dosage de l'azote ammoniacal libéré (Brisou, 1971).

Parmi les méthodes de dosage de l'ammoniac, nous avons opté pour la méthode colorimétrique par réaction au phénol-hypochlorite de Berthelot, mise en œuvre avec l'autoanalyseur Technicon.

L'étude a porté sur les 22 souches d'entérocoques de notre collection déjà éprouvées pour leur activité décarboxylasique. 


\subsubsection{Recherche QuAlitative}

Afin de retenir pour l'étude quantitative les seuls acides aminés susceptibles d'être dégradés, la libération d'ammoniac a été recherchée à l'aide du réactif de Nessler après culture sur un milieu contenant l'acide aminé.

Les souches, après $24 \mathrm{~h}$ d'incubation à $37^{\circ} \mathrm{C}$ en bouillon lactosé, sont ensemencées au taux de 1 p. 100 sur un milieu T LG (tryptone Difco, 0,5 p. 100 ; extrait de levure Mérieux, 0,5 p.100; glucose, 0,05 p. 100 ; phosphate dipotassique, 0,25 p. 100 ; pH 7,0), additionné de 0,3 p. 100 de l'acide aminé à étudier et stérilisé par autoclavage $20 \mathrm{mn}$ à $115^{\circ} \mathrm{C}$. Ce milieu est réparti en tubes à essais à raison de $10 \mathrm{ml}$ par tube.

Les cultures sont incubées $48 \mathrm{~h}$ à $37^{\circ} \mathrm{C}$. Une goutte de réactif de Nessler est alors ajoutée à une goutte de culture. Les cultures qui développent une coloration orange à rouge brique en moins de $1 \mathrm{mn}$ sont considérées comme positives. Des colorations témoins, obtenues par addition d'une goutte du réactif de Nessler à une goutte de culture en milieu T LG, privé de l'acide aminé, permettent d'éviter les erreurs d'interprétation.

Outre les 16 acides aminés de forme DL utilisés en mélange pour étudier l'action globale des entérocoques, les acides aminés suivants ont été essayés : L-arginine, HCL ; L-proline ; L-tryptophane ; DLornithine, HCL ; L-citrulline. L'urée, produit intermédiaire de dégradation de l'arginine, a été également éprouvée.

\subsubsection{Estimation Quantitative}

- Conditions de culture : l'étude quantitative a porté sur les acides aminés ayant donné une réponse positive au test précédent.

Les souches sont au préalable repiquées à $24 \mathrm{~h}$ d'intervalle en bouillon lactosé, puis, sur le milieu T L G, et cultivées à $37^{\circ} \mathrm{C}$. Elles sont ensuite inoculées au taux de 2 p. 100 sur 11 de ce dernier milieu et cultivées durant $24 \mathrm{~h}$ à $37^{\circ} \mathrm{C}$.

Si nécessaire, les cultures sont maintenues à un $\mathrm{pH}$ voisin de 7,0 par additions régulières d'une solution stérile de soude $2 \mathrm{~N}$. La faible teneur du milieu en sucre fermentescible et son pouvoir tampon assez élevé permettent de supprimer, dans la plupart des cas, cette opération.

\section{- Mesure de l'activité enzymatique}

a) Préparation des suspensions cellulaires : les cultures sont centrifugées, $30 \mathrm{mn}$ à $2000 \mathrm{~g}$, à l'aide d'une centrifugeuse MSE Mistral $4 \mathrm{~L}$, réfrigérée à $+4^{\circ} \mathrm{C}$. Les culots cellulaires sont lavés deux fois avec $100 \mathrm{ml}$ de tampon phosphate $\mathrm{M} / 15, \mathrm{pH} 7$ et les cellules récoltées sont mises en suspension à la concentration de 10 p. 100 en tampon mixte acétate-borate-phosphate $0,25 \mathrm{M}$ réglé à $\mathrm{pH} 6$ ou $\mathrm{pH} 8$. 
b) Conditions de réaction : l'activité désaminasique des suspensions cellulaires est déterminée sur les deux acides aminés L-arginine, $\mathrm{HCl}$ et L-sérine ; quelques essais ont porté également sur la L-cystéine, $\mathrm{HCl}$ et sur la L-citrulline. L'acide aminé est mis en solution à 3 p. 1000 en tampon mixte $0,25 \mathrm{M}$ pH 6 ou $\mathrm{pH} 8$.

Les conditions utilisées sont proches de celles préconisées par Kristoffersen et Nelson (1955) et Brisou (1971). Les mélanges réactionnels ont la composition suivante :

Suspension cellulaire . . . . . . . . . . . . $1 \mathrm{ml}$

Solution tamponnée de l'acide aminé ..... . $1 \mathrm{ml}$

La réaction est effectuée dans des tubes à hémolyse soigneusement bouchés, placés au bain-marie durant $2 \mathrm{~h}$ à $45^{\circ} \mathrm{C}$. L'action enzymatique est alors arrêtée par addition de $1 \mathrm{ml}$ d'acide trichloracétique à $36 \mathrm{p} .100$. La solution est ensuite centrifugée à $2500 \mathrm{~g}$ pendant $10 \mathrm{mn}$.

Pour chaque préparation, des témoins sont constitués par des mélanges réactionnels non incubés et traités dans les mêmes conditions. Enfin, il a été vérifié que par incubation de la suspension cellulaire en présence de la solution tampon il n'y avait pas libération d'ammoniac.

c) Dosage de l'ammoniac : les déterminations de l'activité désaminasique sont effectuées sur deux cultures différentes d'une même souche, chaque culture étant elle-même éprouvée en double.

Le dosage de l'ammoniac libéré est réalisé selon la réaction de Berthelot au phénol-hypochlorite, réaction catalysée par le nitroprussiate de sodium qui permet une meilleure évaluation photométrique (Lubochinsky et Zalta, 1954). L'analyse automatique est conduite selon la technique d'Agneray (1961) légèrement modifiée.

\section{RÉACTIFS}

Solution de phosphate disodique

Dissoudre à chaud $338 \mathrm{~g}$ de $\mathrm{HNa}_{2} \mathrm{PO}_{4}, 12 \mathrm{H}_{2} \mathrm{O}$ dans environ 51 l'eau bidistillée.

Solution de soude diluée

Hydroxyde de sodium ... . . . . . . . . . . 80 g

Eau bidistillée . . . . . . . . . . . . . . q.s.p. . . $500 \mathrm{ml}$

Solution tampon

Solution de phosphate disodique .. .. .. .. $4500 \mathrm{ml}$

Solution de soude diluée .............. . $500 \mathrm{ml}$

(Solution filtrée sur verre fritté $n^{\circ} 4$ avant emploi).

Solution de nitroprussiate de sodium

Nitroprussiate à 1 p. 100 dans l'eau distillée . $10 \mathrm{ml}$

Solution tampon . . . . . . . . . . . . . . . . . . . $500 \mathrm{ml}$

Eau bidistillée . . . . . . . . . . . q.s.p. . $1000 \mathrm{ml}$ 
Solution d'hypochlorite de sodium à $0,5^{\circ}$ chlorométrique

Solution d'hypochlorite à $10^{\circ} \ldots \ldots \ldots$. $\ldots \ldots \ldots$..s.

Solution tampon . . . . . . . . . . . . . . . . . $500 \mathrm{ml}$

Eau bidistillée .. . . . . . . . . q.s.p. . $1000 \mathrm{ml}$

Solution de phénol

Phénol aqueux à 90 p. $100 \ldots \ldots$. . . . . . . . 27,75 g

Solution tampon .................... . . $500 \mathrm{ml}$

Eau bidistillée . . . . . . . . . . . q.s.p. . $1000 \mathrm{ml}$

Solution mère de sulfate d'ammonium (Img d'N/ml)

Sulfate d'ammonium (RP) sec . . . . . . . . . . 4,714 g

Eau bidistillée . . . . . . . . . . . . q.s.p. . $1000 \mathrm{ml}$

TECHNIQUE OPÉRATOIRE

La figure 3 schématise les différentes étapes de l'analyse.

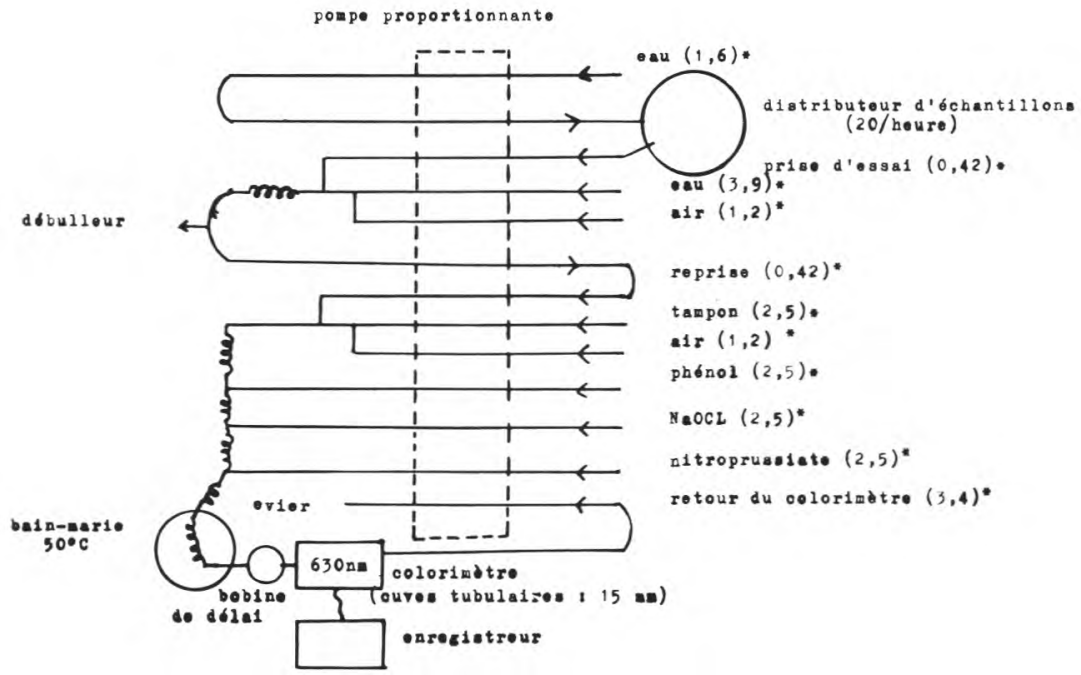

fig. 3

Schéma du dispositif d'autoanalyse pour l'étude des désaminases d'acides aminés

* Débit des tubes en $\mathrm{ml} / \mathrm{mn}$.

L'échantillon est aspiré par la pompe proportionnante, segmenté par de l'air débarrassé d'ammoniac, introduit dans la solution tampon qui l'alcalinise et libère l'ammoniac. Après passage dans une bobine de mélange, il est mis au contact de la solution de phénol et additionné d'hypochlorite de sodium. La réaction, formation d'un dérivé 
d'indophénol, est catalysée par le nitroprussiate et le développement de la coloration assuré par passage dans un bain-marie réglé à $50^{\circ} \mathrm{C}$, pendant $9 \mathrm{mn}$. La densité optique est mesurée à $630 \mathrm{~nm}$. La concentration en ammoniac est calculée par comparaison avec une courbe étalon établie avec une solution de sulfate d'ammonium dans l'intervalle des concentrations $0-100 \mu \mathrm{g}$ d'N par $\mathrm{ml}$.

\section{II. - RESULTATS ET DISCUSSION}

\subsection{Action des entérocoques sur un mélange d'acides aminés}

Pour chaque espèce, l'aptitude à la dégradation des acides aminés a été estimée sur une souche, à partir de deux cultures différentes. Les préparations $P_{1}$ et $P_{2}$ ont été réalisées sur chacune des cultures et les mesures effectuées en double sur chaque préparation. Les résultats, groupés dans le tableau 1, représentent la moyenne de quatre déterminations. Seuls sont notés les résultats positifs exprimés selon le rapport acide aminé présent dans l'essai/acide aminé présent dans le témoin $\times 100$. Tenant compte de la précision de l'estimation, on peut admettre que tout résultat inférieur à 80 p. 100 traduit une dégradation de l'acide aminé correspondant.

S'il y a dégradation d'un acide aminé, à $\mathrm{pH} 5,6$ on peut penser qu'il s'agit d'une réaction de décarboxylation, à 7,8 d'une réaction de désamination. On sait en effet depuis les travaux de Gale (1940 a, 1940 b) et de Gale et Epps (1944), que les bactéries attaquent les acides aminés par décarboxylation en milieu acide, et par désamination en milieu alcalin.

Dans les conditions opératoires retenues, seuls trois acides aminés sont susceptibles d'être attaqués par les entérocoques : la cystéine, la tyrosine et l'arginine.

Selon les espèces, la cystéine paraît être très inégalement dégradée. $S$, faecalis var. liquefaciens et $S$. faecalis ne semblent pas avoir d'action; en revanche, $S$. faecium et $S$. durans manifestent une activité notable. De plus, le système enzymatique responsable paraît être localisé différemment chez ces deux dernières espèces ; chez $S$. durans, seule la préparation $P_{2}$ (surnageant du broyat cellulaire) est active à $\mathrm{pH} 7,8$, alors que chez $S$. faecium, la suspension $\left(\mathrm{P}_{1}\right)$ et le broyat cellulaire $\left(\mathrm{P}_{\mathfrak{2}}\right)$ ont pratiquement la même activité à ce $\mathrm{pH}$. Il est à noter qu'à $\mathrm{pH} 5,6$, aucune activité n'a été mise en évidence sur les quatre espèces. Le fait que la dégradation se manifeste seulement à $\mathrm{pH} 7,8$ pourrait laisser penser qu'il s'agit d'une réaction de désamination.

La tyrosine est attaquée par les quatre espèces, et la dégradation se produit à $\mathrm{pH} 5,6$ et non à $\mathrm{pH} 7,8$ (tab. 1). Dans ce cas il s'agit probablement d'une décarboxylation. Cette hypothèse s'accorde avec 
les travaux de Gale (1940a) qui ont montré que les entérocoques possèdent une tyrosine décarboxylase dont l'activité est optimale vers $\mathrm{pH} 5-5,5$. On observera qu'à $\mathrm{pH}$ 7,8 l'enzyme semble être totalement inactivée. Chez les quatre espèces, les suspensions cellulaires $\left(\mathrm{P}_{1}\right)$ et les surnageants de broyats cellulaires $\left(\mathrm{P}_{2}\right)$ présentent des activités comparables ; on peut en déduire qu'il s'agit d'un système enzymatique endocellulaire, mais cependant capable de manifester son activité sur le milieu environnant. Rappelons que cette décarboxylation est importante en technologie fromagère, car responsable de la présence de tyramine dans les produits affinés (Dahlberg et Kosikowski, 1948).

En ce qui concerne l'arginine, son mécanisme de dégradation est particulier et il sera évoqué dans un chapitre ultérieur.

\subsection{Activité des décarboxylases}

L'activité décarboxylasique a été estimée à deux valeurs de $\mathrm{pH}$ : 4,0 et 5,6. La première a été choisie sur la base des travaux de Gale (1946) qui ont montré que les décarboxylases des acides aminés présentent une activité optimale dans la zone de $\mathrm{pH} 4,0-5,0$; la seconde correspond au $\mathrm{pH}$ de nombreuses pâtes fromagères.

Les déterminations d'activité ont été effectuées en double sur deux cultures différentes de chacune des souches. La reproductibilité est de 96 p. 100 pour les déterminations réalisées à partir d'une même culture, de 80 p. 100 pour celles réalisées à partir de cultures différentes.

L'activité a été mesurée sur des suspensions cellulaires $\left(\mathrm{P}_{1}\right)$. En effet, les résultats obtenus lors de l'étude de l'action des entérocoques sur un mélange d'acides aminés montrent que, sur la tyrosine et l'arginine, les suspensions cellulaires ont une activité sensiblement égale à celle des broyats cellulaires (tab. 1). Les dosages du gaz carbonique libéré par les suspensions ou les broyats de quelques souches ont confirmé ce point.

Les conditions de culture, $16 \mathrm{~h}$ à $37^{\circ} \mathrm{C}$, ont été choisies en fonction des résultats de Gale (1946) qui ont mis en évidence que la décarboxylation de la tyrosine chez $S$. faecalis, était maximale à la fin de la phase active de division cellulaire.

Le milieu de culture T G L utilisé pour la production des cellules est riche en glucose $(20 \mathrm{~g} / 1)$. Les travaux de Gale $(1940 \mathrm{c})$ et de Hosono et Tokita (1969) ont en effet montré que la synthèse des décarboxylases était favorisée par les pH acides ; aussi cultive-t-on, en général, les micro-organismes dans des milieux contenant une notable proportion de glucose ou d'un autre sucre fermentescible, la fermentation qui accompagne la croissance, provoquant une chute de $\mathrm{pH}$ favorable à la production d'enzymes (Gale, 1961). 


\section{TABLEAU 1}

Action des entérocoques sur un mélange d'acides aminés

(Résultats exprimés par le rapport

taux de l'acide aminé de l'essai / taux de l'acide aminé du témoin x 100)

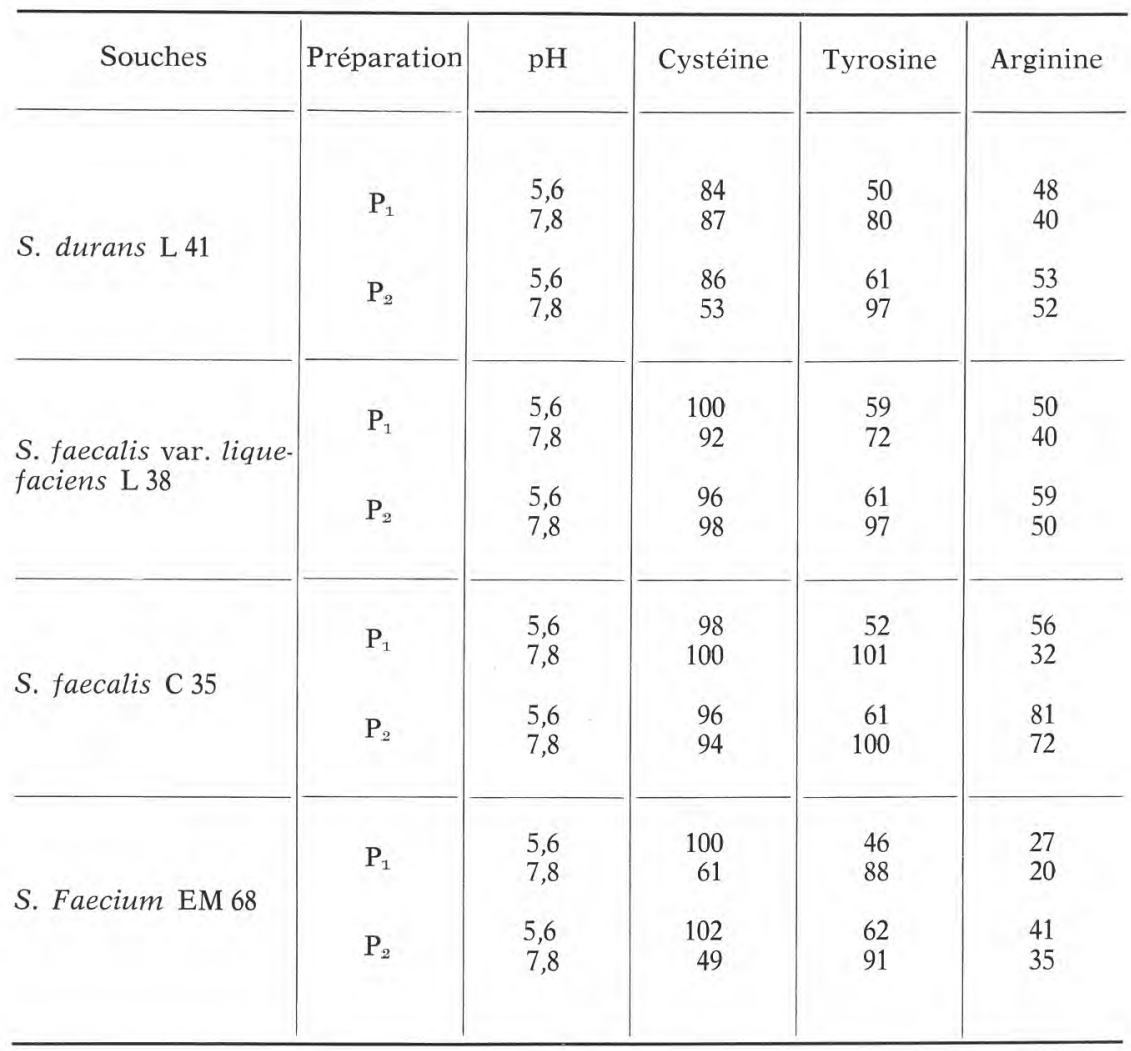

Enfin, le choix du tampon acétate $0,2 \mathrm{M}$ pour la mise en suspension des cellules se justifie par les résultats obtenus par Lagerborg et Clapper (1952), Gale (1961) et Leclerc (1967) qui ont clairement montré que ce tampon était favorable à la manifestation de l'activité de la plupart des décarboxylases.

Ont ainsi pu être mis en évidence : une tyrosine décarboxylase (EC 4.1.1.25)*, une acide glutamique décarboxylase (EC 4.1.1.15) et une production de gaz carbonique à partir de l'arginine.

Ces systèmes enzymatiques paraissent être très inégalement distribués au sein du groupe.

* Position dans la nomenclature internationale des enzymes (1972). 


\section{TABLEAU 2}

Activité de la tyrosine décarboxylase chez les entérocoques

(Résultats exprimés en meq. de $\mathrm{CO}_{2}$ par heure d'incubation)

\begin{tabular}{|c|c|c|c|c|}
\hline \multicolumn{2}{|l|}{ Souches } & $\mathrm{pH}: 4,0$ & $\mathrm{pH}: 5,6$ & $\mathrm{~A} / \mathrm{B}$ \\
\hline S. faecalis var. liquefaciens & $\begin{array}{r}\text { L } 17 \\
\text { L } 25 \\
\text { C } 30 \\
\text { L } 38 \\
\text { L } 39 \\
\text { L } 40 \\
\text { L } 43 \\
\text { EM } 51 \\
\text { EM } 94\end{array}$ & $\begin{array}{l}22 \\
15 \\
22 \\
19 \\
21 \\
21 \\
18 \\
21 \\
23\end{array}$ & $\begin{array}{l}15 \\
12 \\
20 \\
15 \\
19 \\
\frac{18}{15} \\
15\end{array}$ & $\begin{array}{l}1,5 \\
1,2 \\
\overline{0,9} \\
1,4 \\
1,1 \\
\overline{1,2} \\
1,5\end{array}$ \\
\hline S. faecalis & C 35 & 20 & 22 & 0,9 \\
\hline S. faecium & $\begin{aligned} & \text { F } 9 \\
& \text { F } 22 \\
& \text { EM } 68 \\
& \text { EM } 85 \\
& \text { EM } 92 \\
& \text { C } 100\end{aligned}$ & $\begin{array}{l}21 \\
13 \\
22 \\
14 \\
11 \\
16\end{array}$ & $\begin{array}{l}11 \\
16 \\
21 \\
14 \\
16 \\
13\end{array}$ & $\begin{array}{l}1,9 \\
0,8 \\
1,0 \\
1,0 \\
0,7 \\
1,2\end{array}$ \\
\hline S. durans & $\begin{array}{rr}\text { L } & 18 \\
\text { F } & 21 \\
\text { L } & 41 \\
\text { ER } & 115 \\
\text { F } & 122 \\
\text { F } & 123\end{array}$ & $\begin{array}{l}21 \\
20 \\
17 \\
21 \\
15 \\
16\end{array}$ & $\begin{array}{r}14 \\
8 \\
16 \\
16 \\
9 \\
13\end{array}$ & $\begin{array}{l}1,5 \\
2,5 \\
1,1 \\
1,3 \\
1,7 \\
1,2\end{array}$ \\
\hline
\end{tabular}

La tyrosine décarboxylase est présente chez toutes les souches éprouvées (tab. 2). Les différences d'activité enregistrées entre les souches sont assez faibles, et il est difficile d'attribuer à chacune des espèces une activité moyenne caractéristique, significativement différente de celle des autres ; ces résultats concordent avec les données de Gale (1946), Barnes et Ingram (1955) et Deibel (1964 a). On peut toutefois, malgré le petit nombre de souches étudiées, relever certaines tendances ; ainsi, chez $S$. faecalis var. liquefaciens, l'activité semble être un peu plus élevée.

L'activité de l'enzyme est, pour la majorité des souches, plus importante à $\mathrm{pH} 4,0$ qu'à $\mathrm{pH} 5,6$. Ceci est notamment observé chez les espèces $S$. faecalis var. liquefaciens et $S$. durans. Chez $S$. faecium, en revanche, l'activité à $\mathrm{pH}$ 5,6 est souvent supérieure ou égale à celle 
relevée à $\mathrm{pH} 4,0$. On constatera qu'au sein de chacune des espèces le rapport activité à $\mathrm{pH} \mathrm{4,0} \mathrm{/} \mathrm{activité} \mathrm{à} \mathrm{pH} 5,6$ varie assez largement : de 0,9 à 1,5 chez $S$. faecalis var. liquefaciens, de 0,7 à 1,9 chez $S$. faecium et de 1,1 à 2,5 chez $S$. durans.

En ce qui concerne l'acide glutamique, sur les 22 souches essayées, 2 seulement, $S$. faecalis var. liquefaciens EM 51 et $S$. durans $\mathrm{F} 21$, se révèlent aptes à provoquer sa décarboxylation, libérant respectivement 26 et 11 méq. de $\mathrm{CO}_{2}$ par heure d'incubation. Il est à noter que dans l'étude de l'action des entérocoques sur un mélange d'acides aminés, une telle activité n'avait pas été décelée, mais cette étude n'avait porté que sur une seule souche de chaque espèce.

L'activité de l'enzyme se manifeste à $\mathrm{pH} 4,0$ mais non à $\mathrm{pH} \mathrm{5,6,}$ ce qui est en contradiction avec les résultats de Leclerc (1967) selon lesquels l'enzyme, à pH 6,0, conserve encore environ 30 p. 100 de son activité.

Il convient aussi d'observer que dans une étude analogue portant sur 15 souches d'entérocoques, Leclerc (1967) n'avait pu mettre en évidence une acide glutamique décarboxylase. Il est probable que cette discordance s'explique par le petit nombre de souches éprouvées et le fait que l'enzyme n'est guère représentative du groupe microbien.

\subsection{Activité des désaminases}

A priori, compte tenu des résultats enregistrés précédemment (tab. 1), on pouvait s'attendre, dans l'épreuve qualitative avec le réactif de Nessler, à une production d'ammoniac à partir de la cystéine et de l'arginine. Or, cette épreuve a montré que seules sérine et arginine sont susceptibles de subir une dégradation avec libération d'ammoniac. Il apparaît donc que certaines souches d'entérocoques sont capables de désaminer la sérine mais non la cystéine.

L'estimation quantitative de l'activité désaminasique a été réalisée sur les quatre substrats : cystéine, sérine, arginine et citrulline, produit intermédiaire de la dégradation de l'arginine.

Les résultats obtenus, groupés dans le tableau 3, sont exprimés en $\mu \mathrm{g}$ de $\mathrm{NH}_{3}$ libéré par ml de mélange et par heure d'incubation. Les chiffres notés correspondent à la moyenne de quatre mesures, la reproductibilité étant de 95 p. 100 environ, aussi bien pour les déterminations réalisées à partir d'une même culture que pour celles effectuées à partir de deux cultures différentes de la souche.

Comme dans le cas des décarboxylases, l'activité a été estimée sur des suspensions cellulaires, les résultats enregistrés lors de l'étude de l'action des entérocoques sur un mélange d'acides aminés ayant montré qu'à pH 7,8, sur l'arginine, l'activité des suspensions cellulaires était souvent supérieure à celle des broyats. Il a toutefois été vérifié, sur quelques souches, que, à partir de la sérine et de l'argi- 
TABLEAU 3

Activité de la sérine désaminase chez les entérocoques (Résultats exprimés en $\mu \mathrm{g}$ de $\mathrm{NH}_{3}$ par $\mathrm{ml}$ de mélange et par heure d'incubation)

\begin{tabular}{|c|c|c|c|}
\hline \multicolumn{2}{|l|}{ Souches } & $\mathrm{pH}: 5,6$ & $\mathrm{pH}: 8,1$ \\
\hline S. faecalis var. liquefaciens & EM 51 & 0 & 17 \\
\hline S. faecalis & C 35 & 0 & 0 \\
\hline S. faecium & $\begin{array}{cc}\text { F } 9 \\
\text { F } 22 \\
\text { EM } 68 \\
\text { EM } 85 \\
\text { C } 100\end{array}$ & $\begin{array}{l}0 \\
0 \\
0 \\
0 \\
0\end{array}$ & $\begin{array}{r}10 \\
24 \\
14 \\
5 \\
5\end{array}$ \\
\hline S. durans & $\begin{array}{cc}\text { L } & 18 \\
\text { F } & 21 \\
\text { L } & 41 \\
\text { ER } & 115 \\
\text { F } & 122 \\
\text { F } & 123\end{array}$ & $\begin{array}{l}0 \\
0 \\
0 \\
0 \\
0 \\
0\end{array}$ & $\begin{array}{r}6 \\
7 \\
7 \\
12 \\
12 \\
20 \\
27\end{array}$ \\
\hline
\end{tabular}

nine, les cellules entières produisent au moins autant d'ammoniac que les cellules éclatées.

L'activité désaminasique des 22 souches d'entérocoques a été estimée à deux valeurs de $\mathrm{pH}, 5,6$, correspondant au $\mathrm{pH}$ de nombreux fromages, et 8,1 , voisin de l'optimum d'action des désaminases (Kristoffersen et Nelson, 1955 ; Brisou, 1971).

Le milieu de culture utilisé contient très peu de glucose $(0,5 \mathrm{~g} / \mathrm{l})$. Une forte addition de sucre, dont la fermentation provoque un abaissement du $\mathrm{pH}$ du milieu de culture, constitue en effet un facteur d'inhibition de l'activité désaminasique (Gale et Stephenson, 1938 ; Niven et al., 1942 ; Deibel, 1964 b).

Les conditions d'incubation du mélange réactionnel $\left(2 \mathrm{~h} / 45^{\circ} \mathrm{C}\right)$ sont celles qui paraissent les plus favorables à la détermination de l'activité enzymatique, une relation linéaire entre le temps et la quantité de $\mathrm{NH}_{3}$ libérée ayant été ainsi observée (Oginsky et Gehrig, 1952 a ; Kristoffersen et Nelson, 1955).

Les résultats mentionnés dans le tableau 3 concernent seulement la sérine. Il apparaît nettement que l'activité sérine désaminase (L-sérine déshydratase : EC 4.2.1.13.) est très variable au sein du 
groupe des entérocoques. Seule la souche de $S$. faecalis var. liquefaciens EM 51 possède une telle activité, alors que l'enzyme est présente chez toutes les souches de $S$. faecium et $S$. durans éprouvées. Chez ces deux dernières espèces, les activités varient, selon les souches dans des limites assez larges : de 5 à $24 \mathrm{chez} S$. faecium, de 6 à $20 \mathrm{chez}$ $S$. durans. Il est également intéressant de noter qu'à $\mathrm{pH} 5,6$ l'enzyme ne manifeste aucune action; il s'agit donc d'un système qui n'est capable d'intervenir que dans les pâtes fromagères dont le $\mathrm{pH}$ évolue vers la neutralité. Cette remarque ne s'accorde pas avec les travaux de Kristoffersen et Nelson (1955) qui ont relevé, chez Lactobacillus casei, la présence d'une sérine désaminase encore active à pH 5,6. Une autre contradiction apparaît entre nos résultats et ceux de Deibel et Niven (1960) qui signalent que seule l'espèce $S$. faecalis est capable de dégrader la sérine avec production d'ammoniac. Enfin, il convient de rappeler que lors de nos premiers essais (tab. 1), nous n'avions pas mis en évidence d'activité sérine désaminase sur aucune des souches d'entérocoques.

En ce qui concerne la cystéine, il a été observé (tab. 1) que cet acide aminé semblait être attaqué très diversement selon les espèces d'entérocoques, et seulement à $\mathrm{pH} 7,8$. En revanche, aucun dégagement d'ammoniac n'a pu être mis en évidence lors de l'épreuve qualitative ou avec la méthode de Berthelot. L'enzyme responsable de la dégradation n'est donc probablement pas une désaminase (Kristoffersen et Nelson, 1955).

D'autres systèmes enzymatiques peuvent, en effet, dégrader la cystéine selon divers mécanismes. Ainsi, la cystéine lyase (EC 4.4.1.10.) est capable, en présence de sulfite, de transformer cet acide aminé en acide cystéique et hydrogène sulfuré ; la cystéine dioxygénase (EC 1.13.11.20.), en présence d'oxygène, peut transformer la cystéine en cystine ; la cystéine amino-transférase (EC 2.6.1.3.) attaque la cystéine en présence d'acide $\alpha$ cétoglutarique et forme de l'acide mercaptopyruvique et de l'acide glutamique.

Il apparaît donc difficile, en raison du nombre des chaînes métaboliques possibles, de désigner le système enzymatique, actif sur la cystéine, produit par $S$. faecium et $S$. durans. Seule, la recherche des composés formés au cours de la réaction permettrait son identification.

\section{III. - APTITUDE A LA DEGRADATION DE L'ARGININE}

L'hydrolyse de l'arginine par les streptocoques, particulièrement étudiée par Hills (1940), est, depuis longtemps, classiquement utilisée pour la différenciation des espèces (Ayers et al., 1921 ; Niven et al., 1942). 
De nombreux travaux ont permis de démonter le mécanisme de cette hydrolyse et ont mis en évidence que l'enzyme, appelée « arginine dihydrolase » (Hills, 1940), était en fait un système complexe. La réaction commence par une hydrolyse de l'arginine en citrulline et ammoniac, et l'enzyme responsable est désignée « métarginase " (Akamatsu et Sekine, 1951), " arginine désimidase " (Oginsky et Gehrig, 1952 a et 1952 b ; Slade, 1953), ou " arginine désiminase " (EC 3.5.3.6.) (Roche et Lacombe, 1952 ; Knivett, 1952 ; Ratner, 1954 ; Schimke et Barile, 1963). Il se produit ensuite une dégradation de la citrulline en ornithine, ammoniac et gaz carbonique. D'abord considérée comme une simple hydrolyse catalysée par la citrullinase (EC 3.5.1.20.) (Akamatsu et Sekine, 1951), cette réaction impliquerait, en réalité, un couplage avec une phosphorylation de l'adénosine diphosphate (Slade et Slamp, 1952 ; Korzenovsky et Werkman, 1952 et 1953 ; Oginsky et Gehrig, 1952 b et 1953 ; Slade 1953 et 1954 ; Knivett, 1954) :

$$
\text { Citrulline + A D P }+\mathrm{H}_{3} \mathrm{PO}_{4} \stackrel{\mathrm{H}_{2} \mathrm{O}}{\longrightarrow} \text { Ornithine + A T P }+\mathrm{NH}_{3}+\mathrm{CO}_{2} .
$$

Chez $S$. faecium il a été établi que la réaction s'effectue en deux temps, avec formation d'un intermédiaire phosphorylé, le carbamylphosphate (Jones et al., 1955 ; Jones, 1963).

L'enzyme de dégradation de la citrulline est actuellement assimilée à l'ornithine carbamoyltransférase (EC 2.1.3.3.) (Thoai et Robin, 1972).

Le mécanisme de dégradation de l'arginine, par les entérocoques, apparaît donc original. Le gaz carbonique libéré ne provient pas d'une simple réaction de décarboxylation, ni l'ammoniac d'une véritable réaction de désamination.

\subsection{Action globale des entérocoques}

Les quatre espèces d'entérocoques sont aptes à dégrader l'arginine (tab. 1) et l'attaque apparaît très rapide, quels que soient le mode de préparation $\left(\mathrm{P}_{1}\right.$ ou $\left.\mathrm{P}_{2}\right)$ et le $\mathrm{pH}$ d'action $(5,6$ ou 7,8$)$.

Dans tous les cas, la DL-arginine est dégradée à environ 50 à 80 p. 100 , ce qui laisse penser que, la forme L étant totalement attaquée, 0 à 30 p. 100 de la forme $\mathrm{D}$ le sont également. Ce résultat peut s'expliquer par la présence, chez certaines souches, d'une racémase (EC 5.1.1.9.).

Chez S. faecalis var. liquefaciens, $S$. faecium et $S$. durans, les activités des préparations $\mathrm{P}_{1}$ et $\mathrm{P}_{2}$ sont sensiblement égales. Chez $S$. faecalis, une différence d'activité est observée entre les deux types de préparations. Il s'agit donc probablement de systèmes enzymatiques qui pourraient être localisés différemment à l'intérieur de la cellule. 


\subsection{Libération de gaz carbonique}

Sur les 22 souches d'entérocoques éprouvées, 11 se révèlent aptes à libérer du $\mathrm{CO}_{2}$ à partir de l'arginine, et, d'une espèce à l'autre, des différences notables sont observées (tab. 4). Ainsi, toutes les souches

\section{TABLEAU 4}

Libération de $\mathrm{CO}_{2}$ à partir de l'arginine par les entérocoques (Résultats exprimés en meq. de $\mathrm{CO}_{2}$ par heure d'incubation)

\begin{tabular}{|c|c|c|c|}
\hline Souches & & $\mathrm{pH}: 4,0$ & $\mathrm{pH}: 5,6$ \\
\hline S. faecalis var. liquefaciens & EM 51 & 15 & 8 \\
\hline S. faecalis & C 35 & 0 & 0 \\
\hline S. faecium & $\begin{aligned} \text { F } & 9 \\
\text { F } & 22 \\
\text { EM } & 68 \\
\text { EM } & 85 \\
\text { EM } & 92 \\
\text { C } & 100\end{aligned}$ & $\begin{array}{r}18 \\
17 \\
0 \\
0 \\
17 \\
15\end{array}$ & $\begin{array}{l}0 \\
0 \\
0 \\
0 \\
0 \\
9\end{array}$ \\
\hline S. durans & $\begin{aligned} \text { L } & 18 \\
\text { F } & 21 \\
\text { L } & 41 \\
\text { ER } & 115 \\
\text { F } & 122 \\
\text { F } & 123\end{aligned}$ & $\begin{array}{l}22 \\
17 \\
16 \\
13 \\
23 \\
22\end{array}$ & $\begin{array}{r}9 \\
9 \\
9 \\
9 \\
10 \\
9\end{array}$ \\
\hline
\end{tabular}

de $S$. durans possèdent le système enzymatique responsable. Chez $S$. faecium, il est seulement présent sur 4 des 6 souches essayées, et chez $S$. faecalis var. liquefaciens, une souche seulement sur 9 se révèle active.

Les aptitudes à produire du gaz carbonique, à $\mathrm{pH} 4$, sont peu différentes d'une souche à l'autre. Exprimées en meq de $\mathrm{CO}_{2}$ libéré par heure d'incubation, elles sont du même ordre de grandeur que les activités tyrosine décarboxylase. En revanche, à pH 5,6, la dégradation de l'arginine est très fortement inhibée ; pour certaines souches elle l'est totalement, et pour d'autres, elle est réduite d'environ 50 p. 100. 
La synthèse de ce système enzymatique chez les entérocoques peut, semble-t-il, s'effectuer selon des mécanismes différents. Ainsi, certaines cultures développées sur un lot de trypticase pauvre en arginine (trypticase 1) ne possèdent aucune activité (tel est le cas pour $S$. faecium et $S$. durans), d'autres au contraire ont un potentiel d'action enzymatique égal à celui des cellules récoltées sur milieu riche en arginine (trypticase 2); il en est ainsi chez $S$. faecalis var. liquefaciens EM 51.

\begin{tabular}{l|c|c}
\multicolumn{1}{c|}{ Souches } & Trypticase 1 & Trypticase 2 \\
\hline & & 15 \\
S. faecalis var. liquefaciens EM 51 & 0 & 15 \\
S. faecium F 22 & 0 & 17 \\
S. faecium EM 92 & 0 & 17 \\
S. durans F 21 & & \\
\end{tabular}

Une hypothèse peut être émise : l'arginine dihydrolase est un système induit et le taux d'arginine disponible dans le milieu 1 serait inférieur au seuil d'induction pour les souches de $S$. faecium et de $S$. durans; en revanche, en ce qui concerne $S$. faecalis var. liquefaciens, le seuil d'induction pourrait être plus faible ou le taux d'arginine disponible dans le milieu 1 serait accru en raison de l'action protéolytique de la souche. Il est d'ailleurs connu que d'autres systèmes enzymatiques actifs sur les acides aminés, comme les décarboxylases, sont des systèmes induits (Brisou, 1971).

Enfin, quelques essais ont permis de confirmer qu'il n'y a pas production de $\mathrm{CO}$ à partir de l'ornithine (Møller, 1955 ; Leclerc, 1967), cet acide aminé n'est donc pas dégradé en putrescine par une ornithine décarboxylase (EC 4.1.1.17.), ni à partir de l'urée (Niven et al., 1942) sous l'action d'une uréase (EC 3.5.1.5.).

\subsection{Libération d'ammoniac}

L'ammoniac est libéré par les entérocoques à partir de l'arginine au cours de chacune des deux réactions catalysées par le système " arginine dihydrolase » (Hills, 1940).

Toutes les souches éprouvées (tab. 5) sont aptes à produire du $\mathrm{NH}_{3}$, mais le niveau de production est variable selon les espèces. A pH 5,6, chez $S$. faecalis var. liquefaciens, espèce la plus active, il est pratiquement constant et proche de $50 \mu \mathrm{g}$; chez $S$. faecium, il est compris entre 28 et $57 \mu \mathrm{g}$, et chez $S$. durans, entre 13 et $50 \mu \mathrm{g}$. Deibel 


\section{TABLEAU 5}

Libération de $\mathrm{NH}_{3}$ à partir de l'arginine par les entérocoques (Résultats exprimés en $\mu \mathrm{g}$ de $\mathrm{NH}_{3}$ par $\mathrm{ml}$ de mélange et par heure d'incubation)

\begin{tabular}{|c|c|c|c|c|}
\hline \multicolumn{2}{|l|}{ Souches } & $\underset{(\mathrm{A})}{\mathrm{pH}: 5,6}$ & $\begin{array}{c}\mathrm{pH}: 8,1 \\
\text { (B) }\end{array}$ & $\mathrm{A} / \mathrm{B}$ \\
\hline S. faecalis var. liquefaciens & $\begin{array}{rr}\text { L } & 17 \\
\text { L } & 25 \\
\text { C } & 30 \\
\text { L } & 38 \\
\text { L } & 39 \\
\text { L } & 40 \\
\text { EM } & 51 \\
\text { EM } & 89 \\
\text { EM } & 94\end{array}$ & $\begin{array}{l}50 \\
48 \\
40 \\
54 \\
48 \\
52 \\
\frac{48}{2}\end{array}$ & $\begin{array}{l}56 \\
36 \\
49 \\
33 \\
56 \\
32 \\
35 \\
46 \\
31\end{array}$ & $\begin{array}{l}0,90 \\
\overline{0} \\
0,98 \\
1,21 \\
0,96 \\
1,50 \\
1,49 \\
\overline{1,55}\end{array}$ \\
\hline S. faecalis & C 35 & 6 & 21 & 0,29 \\
\hline S. faecium & $\begin{array}{cc}\text { F } 9 \\
\text { F } 22 \\
\text { EM } 68 \\
\text { EM } 85 \\
\text { C } 100\end{array}$ & $\begin{array}{l}28 \\
36 \\
45 \\
49 \\
57\end{array}$ & $\begin{array}{l}27 \\
36 \\
27 \\
32 \\
32\end{array}$ & $\begin{array}{l}1,04 \\
1,0 \\
1,67 \\
1,53 \\
1,78\end{array}$ \\
\hline S. durans & $\begin{array}{cc}\text { L } & 18 \\
\text { F } & 21 \\
\text { L } & 41 \\
\text { ER } & 115 \\
\text { F } & 122 \\
\text { F } & 123\end{array}$ & $\begin{array}{l}25 \\
13 \\
27 \\
50 \\
43 \\
46\end{array}$ & $\begin{array}{l}22 \\
34 \\
32 \\
52 \\
21 \\
20\end{array}$ & $\begin{array}{l}1,14 \\
0,38 \\
0,84 \\
0,96 \\
2,05 \\
2,30\end{array}$ \\
\hline
\end{tabular}

(1964 b) a mis en évidence que le système enzymatique agit plus tardivement chez $S$. faecium que chez $S$. faecalis var. liquefaciens, mais que la quantité d'ammoniac finalement libérée est à peu près la même.

$\mathrm{A} \mathrm{pH} 8,1, \mathrm{pH}$ favorable à l'action des désaminases, les quantités de $\mathrm{NH}_{3}$ libérées sont en général plus faibles qu'à $\mathrm{pH} 5,6$. Ce résultat concorde avec les travaux de Niven et al. (1942) et de Oginsky et Gehrig (1952 b) qui ont montré que l'arginine désiminase a un $\mathrm{pH}$ optimal situé vers 6,3-6,8, et avec les observations de Schmidt et al. (1952) selon lesquelles la dégradation de la citrulline s'effectue préférentiellement vers $\mathrm{pH} \mathrm{5,5.}$ 
Les rapports activité à $\mathrm{pH} 5,6$ / activité à $\mathrm{pH} 8,1(\mathrm{~A} / \mathrm{B})$ sont variables d'une souche à l'autre, mais, dans l'ensemble, ils sont proches de la valeur 1,28 mentionnée par Niven et al. (1942).

Il apparaît ainsi que tous les entérocoques produisent de l'ammoniac à partir de l'arginine, mais que tous n'ont pas la faculté de libérer du gaz carbonique. On doit donc penser que seules certaines souches sont aptes à catalyser les deux réactions :

$$
\begin{aligned}
& \text { Arginine } \longrightarrow \text { Citrulline }+\mathrm{NH}_{3} \\
& \text { et Citrulline }
\end{aligned}
$$

Pourtant, il a été montré que les suspensions cellulaires d'entérocoques qui produisent $\mathrm{CO}_{2}$ et $\mathrm{NH}_{3}$ à partir de l'arginine n'attaquent la citrulline que très lentement (Oginsky et Gehrig, 1952 a). Nousmêmes avons d'ailleurs observé que les souches aptes à libérer $\mathrm{CO}_{2}+\mathrm{NH}_{3}$ ne dégradent la citrulline que si elles sont sous forme de broyat cellulaire. Les souches ne produisant pas $\mathrm{CO}_{2}+\mathrm{NH}_{3}$ à partir de l'arginine, à l'état de suspension, sont, elles aussi, capables de dégrader la citrulline lorsqu'elles sont sous forme de broyat.

Sans doute y a-t-il là certaines contradictions.

On peut cependant émettre l'hypothèse que le système « arginine dihydrolase " existe chez tous les entérocoques, à l'intérieur de la cellule, et que la paroi de celle-ci est imperméable à la citrulline. Chez certaines souches ce système serait capable de se manifester à partir des suspensions dans la mesure où l'arginine pénètre à l'intérieur de la cellule. Elle y serait dégradée en citrulline et $\mathrm{NH}_{3}$, et celle-ci, à son tour, transformée en ornithine, $\mathrm{CO}_{2}$ et $\mathrm{NH}_{3}$. Chez d'autres, le système actif sur l'arginine serait lié à la paroi ; il pourrait agir sur le substrat à l'extérieur de la cellule, mais la citrulline formée ne pourrait être dégradée.

\section{CONCLUSION}

Finalement, les activités décarboxylasique et désaminasique, chez les entérocoques, paraissent bien être très limitées, notamment par le nombre d'acides aminés susceptibles d'être dégradés selon ces mécanismes (Gale, 1946 ; Deibel, 1964 a ; Kurmann et Schilt, 1973).

Les systèmes suivants ont été décelés :

- un acide glutamique décarboxylase, à $\mathrm{pH}$ 4,0 uniquement, chez 10 p. 100 des souches ;

- un système actif sur la cystéine, à $\mathrm{pH} 7,8$, chez $S$. faecium et S. durans;

- une tyrosine décarboxylase, à pH 5,6, chez toutes les souches éprouvées ;

- une sérine déshydratase, à pH 8,1, chez 50 p. 100 des souches ;

- une "arginine dihydrolase », à pH 4,0 et 5,6, chez 50 p. 100 des souches. 
L'intervention des entérocoques sur le développement de la saveur et de l'arôme des fromages doit, dans ces conditions, être assez faible. Il n'y a guère que deux acides aminés qui sont susceptibles d'être fortement dégradés : la tyrosine en tyramine et l'arginine en citrulline et ornithine.

\section{$R$ és u m é}

Au cours de l'affinage des fromages, les acides aminés libérés par l'hydrolyse des protéines peuvent être, à leur tour, transformés et donner naissance à d'autres composés qui participent au développement de la saveur et de l'arôme des pâtes. Une étude des caractères technologiques d'un groupe microbien ne peut donc ignorer son aptitude à la dégradation des acides aminés.

Après une estimation de l'aptitude globale des entérocoques à l'attaque d'un mélange d'acides aminés, les activités décarboxylasique et désaminasique du groupe ont été déterminées par dosages du gaz carbonique et de l'ammoniac libérés.

L'équipement en enzymes actives sur les acides aminés paraît, chez les entérocoques, être limitée. Le nombre de substrats susceptibles d'être dégradés est en effet très faible; les seuls acides aminés concernés sont la tyrosine, la sérine et l'arginine. Les systèmes enzymatiques décelés sont les suivants : tyrosine décarboxylase, sérine déshydratase et arginine dihydrolase.

\section{S u m m a r y}

CONTRIBUTION TO THE STUDY OF ENTEROCOCCI AND OF THEIR TECHNOLOGICAL ABILITIES

ABILITY TO THE BREAKDOWN OF AMINO-ACIDS

During the cheese-ripening, the liberated amino-acids by the hydrolysis of proteins are also able to be transformed and to produce other compounds, which have a role in the flavour and aroma of cheeses. A study of technological characters of a microbial group cannot therefore leave out of account its ability of amino-acids degradation.

After an estimation of the total ability of enterococci to attack a mixture of amino-acids, the decarboxylasic and deaminasic activities of the group have been determined by estimating liberated carbon dioxyd and ammonia.

The activity of active enzymes on the amino-acids seems to be limited concerning the enterococci. The number of substrates which are susceptible to be degraded, is effectively weak. Only the tyrosin, serin and arginin are affected. The tested enzymatic systems are the 
followings : tyrosin decarboxylase, serin dehydratase and arginin dihydrolase.

Reçu pour publication le 15 mars 1974.

\section{Bibliographie}

Agneray (J.) (1961). - Dosage automatique de l'azote ammoniacal dans les minéralisats. Annls. Biol. chimique, 19, (1-2), 115.

Akamatsu (S.) et Sekine (T.) (1951). - J. Biochem., Tokyo, 38, 349, cité par Oginsky (E. L.) et Gehríg (R. F.) (1952 a), J. biol. Chem., 198, 791.

Ayers (S. H.), RupP (P.) and Mudge (C. S.) (1921). - The production of ammonia and carbon dioxide by streptococci. J. infect. Dis., 29, 235.

BAchrach (U.), SEgal (M.) and Rozansky (R.) (1958). - Effect of tetracyclines on formation of amines by bacteria. Proc. Soc. Exptl. Biol. Med., 97, 874.

BARNES (E. M.) and InGRAM (M.) (1955). - The identity and origin of faecal streptococci in canned hams. Annls. Inst. Pasteur, Lille, 7, 115.

Brisou (J.) (1971). - Techniques d'enzymologie bactérienne. Masson et Cie Ed., Paris.

DACRE (J. C.) (1953). - Cheddar-cheese flavour and its relation to tyramine production by lactic acid bacteria. J. Dairy Res., 20, 217.

DAHLberg (A. C.) and Kosikowski (F. V.) (1948). - The relationship of the amount tyramine and the numbers of Streptococcus faecalis in the intensity of flavour in American Cheddar-cheese. J. Dairy., 31, 305.

Deibet. (R. H.) and Nrven (C.F.) (1960). - Lipoic acid and the fermentation of serine and malate by Streptococcus faecalis. Bact. Proc, P. 54.

Derbel (R. H.) (1964 a), - The group D streptococci. Bact, Rev., 28, (3), 330.

Detbel (R. H.) (1964 b). - Utilization of arginine as an energy source for the growth of Streptococcus faecalis. J. Bact, 87, (5), 988.

Do Ngoc (M.) Lenoir (J.) et CHoIsy (C.) (1971). — Les acides aminés libres des fromages affinés de Camembert, Saint-Paulin et Gruyère de Comté. Revue Lait. Fr. "Industrie Lait », 288, 447.

Enzyme Nomenclature (1972). - Commission on biochemical nomenclature. Elsevier Scientific Publishing Company Ed., Amsterdam.

GALE (E. F.) and STEPHENSON (M.) (1938). - Factors influencing bacterial deamination ; factors influencing the activity of DL-Serine deaminase in Bacterium coli. Biochem. J., 32, 392.

GALE (E. F.) (1940 a). - The production of tyramine by Streptococcus faecalis. Biochem. J., 34, 846.

GALE (E.F.) (1940 b). - The production of putrescine from L (+) arginine by Bacterium coli in symbiosis with Streptococcus faecalis. Biochem. J., 34, 853.

GALE (E. F.) (1940 c). - The production of amine by bacteria. Biochem. J., 34, 392.

Gale (E. F.) et Epps (H. M. R.) (1944). - Biochem. J., 38, 232. Cité par Gale (E. F.) (1946). - The bacterial amino acid decarboxylases. Adv. Enzymol., 6, I.

GALE (E. F.) (1960), - The bacterial amino acid decarboxylases. In " Advances in Enzymology », 6, 1-32. F.F. Nord. Ed., Interscience Publishers Inc., New-York.

GALE (E. F.) (1961). - Determination of amino acids by use of bacterial amino acid decarboxylases. In " Methods of Biochemical Analysis ", 4, 285-306. D. Glick Ed., New-York. 
Hills (G. M.) (1940), - Ammonia production by pathogenic bacteria. Biochem. J., 34, 1057.

Hosono (A.) and Tокіта (F.) (1969). - Studies on the decarboxylation of amino acids by Brevibacterium linens. Jap. J. zootech. Sci., 40, (12), 544.

JACQuet J. et Lenoir (J.) (1969). - Mécanismes intimes de l'affínage des fromages. Economie et Médecine animales, 10, (1), 38.

Jones (M. E.), SPector (L.) and LipMann (F.) (1955). - Carbamyl phosphate, the carbamyl donor in enzymatic citrulline synthesis. J. Am. chem. Soc., 77, 819.

Jones (M. E.) (1963). - Carbamyl phosphate. Science, 140, 1373.

KING (H. K.) and Fletcher (L. I.) (1950). - The production of $\gamma$-amino-butyric acid by Bacterium coli Wilson type I. J. gen. Microbiol., 4, 238.

KNIVETT (V. A.) (1952). - Citrulline as an intermediate in the breakdown of arginine by Streptococcus faecalis. Biochem. J., 50, p. XXX.

KNivetT (V, A.) (1954), - Phosphorylation coupled with anaerobic breakdown of citrulline. Biochem. J., 56, 602.

Korzenovsky (M.) and Werkman (C. H.) (1952). - Bacterial metabolism of arginine. Archs. Biochem. Biophy., 41, 233.

Korzenovsky (M.) and Werkman (C. H.) (1953). - Conversion of citrulline to ornithine by cell-free extracts of Streptococcus lactis. Archs. Biochem. Biophys., 46, 174.

Kosikowski (F. V.) and DaHLBERG (A. C.) (1948). - The tyramine content of cheese. J. Dairy Sci., 31, (4), 293.

Kosikowski (F. V.) et Mocouot (G.) (1958). - Progrès de la technologie du fromage, 137-47. Organisation des Nations Unies pour l'Alimentation et l'Agriculture, Rome.

Kristoffersen (T.) and Nelson (F.E.) (1955). - Degradation of amino-acid by Lactobacillus casei and some factors influencing deamination of serine. Appl. Microbiol., 3, 268.

Kurmann (J. L.) und Schilt (P.) (1973), - Das Verhälten gasbildender Streptokokken in Emmentalerkäsen. Schweiz. Milchztg. (Lait. Romand), 9, S 57-58.

Lagerborg (V.A.) and Clapper (W. E.) (1952). - Amino acid decarboxylases of lactic acid bacteria. J. Bact., 63, 393.

LECLERC (H.) (1966). - Automation des analyses microbiologiques : application à la mesure des décarboxylases bactériennes. Annls. Inst. Pasteur, Lille, $17,21-32$.

Leclerc (H.) (1967). - Mise en évidence de la décarboxylase de l'acide glutamique chez les bactéries à l'aide d'une méthode automatique. Annls. Inst. Pasteur, Lille, 112, (6), 713.

Lestrovaya (N. N.) and Mardashev (S. V.) (1960). - The effect of some halogen derivatives of phenylanine on the decarboxylases of Streptococcus faecalis. Biokhimiya, 25, 227.

Lubochinsky (B.) et ZaLTa (J. P.) (1954). - Microdosage colorimétrique de l'azote ammoniacal. Butl. Soc. Chim. Biol., 36, 1363.

Mc Gilvery (R. W.) and CoHeN (P. P.) (1948). - The decarboxylation of L-Phenylalanine by Streptococcus faecalis R. J. Biol Chem., 174, 813.

MAHLER (H. R.) and CORDES (E. H.) (1968). - Biological chemistry. Harper International Edition, 686-689, New-York.

M $\varnothing$ LLER (V.) (1955). - Simplified tests for some amino acid decarboxylases and for the arginine dihydrolase system. Acta path. microbiol. scand., 36, 158.

Niven (C. F.) Jr., Smiley (K. L.) and Sherman (J. M.) (1942). - The hydrolysis of arginine by streptococci. J. Bact., 43, 651 . 
OGINSKY (E. L.) and Gehrig (R.F.) (1952a). - The arginine dihydrolase system of Streptococcus faecalis. I. Identification of citrulline as an intermediate. J. biol. Chem., 198, 791.

Oginsky (E. L.) and Gehrig (R. F.) (1952 b). - The argine dihydrolase system of Streptococcus faecalis. II. Proporties of arginine desimidase. J. biol Chem., 198, 799.

Oginsky (E.L.) and Gehrig (R.F.) (1953). - The arginine dihydrolase system of Streptococcus faecalis. III. The decomposition of citrulline. J. biol. Chem., 204,721 .

Proom (H.) and WoIwop (A. J.) (1949). - The distribution of glutamic acid decarboxylase in the family Enterobacteriaceae examined by a simple chromatographic method. J. gen Microbiol., 5, 681.

Raibaud (P.), Herren (Ruth.), Mocouot (G.) et Kosikowski (F. V.) (1959). - Mise en évidence dans certains fromages de systèmes enzymatiques actifs sur la tyrosine. Annls Techn., 11, 117.

RATNER (S.) (1954). - Urea synthesis and metabolism of arginine and citrulline. Adv. Enzymol., 15, 319.

Roche (J.) et LAcombe (G.) (1952). - Sur l'arginine désaminase et sur la formation enzymatique de citrulline par les levures. Biochim. Biophs. Acta., 9, 687.

Schimke (R. T.) and Barlile (M.F.) (1963). - Arginine metabolism in pleuropneumonia-like organisms isolated from mammalian cell culture. J. Bact., 86, 195.

Schmidt (G. C.), Logan (M. A.) and Tytell (A. A.) (1952). - The degradation of arginine by Clostridium perfringens (BPGK). Federation Proc., 11, 283.

Schmidt (J. L.) et Lenoir (J.) (1972 a). - Contribution à l'étude des entérocoques et de leurs aptitudes technologiques (I). Lait, 52, (518), 536.

Schmidt (J. L.) et Lenoir (J.) (1972 b). - Contribution à l'étude des entérocoques et de leurs aptitudes technologiques (II). Lait, 52, (519-520), 664.

Sharpe (M. E.) (1948). - Some biochemical characteristics of group D streptococci isolated from infants'faeces, with special reference to their tyrosine decarboxylase activity. Proc. soc. Applied Bact., 11-12, 13.

SilvermanN (G. J.) (1954). - The qualitative and quantitative determination of certain nitrogenous compounds in Cheddar-cheese made from raw and pasteurized milk. Thèse de Doctorat. Cornell University, Itaca, New-York.

SLAdE (H. D.) and SLAMP (W. C.) (1952). - The formation of arginine dihydrolase by streptococci and some properties of the enzyme system. J. Bact., 64, 455.

SLADE (H. D.) (1953). - Hydrolysis of arginine by soluble enzymes of Streptococcus faecalis. Arch. Biochem. Biophy., 42, 201-211.

SLADE (H.D.) (1954). - The metabolism of amino acids by streptococci. In "Streptococcal infections ", M. Mc Carty Ed., 65-86, University Press, NewYork,

ThoAi (N. V.) et Robin (Y.) (1972). - Ornithine et arginine. In " Traité de biochimie générale ", tome 3, $3^{\circ}$ fascicule, 252-254, Masson et Cie Ed., Paris.

Worwod (A. J.) (1949). - A technique for examining large numbers of bacterial culture filtrates by partition chromatography. J. gen. Microbiol., 3, 312.

Wood (W. A.) and Gunsalus (I. C.) (1949). - Serine and threonine deaminases of Escherichia coli; activators for a cell-free enzyme. J. biol. Chem., 181, 171. 